\title{
Uso e interpretación de Zacarías 9,9-10 en el Nuevo Testamento
}

La perícopa de Zacarías 9,9-ıo pertenece a la segunda parte (caps, 9-14) del libro intitulado con el nombre de tal profeta, cuyo contenido puede enmarcarse, en general, dentro de la literatura profética apocalíptica. Prácticamente contiene todo un programa escatológico, que trasciende el estado contingente de la situación histórica, orientándose hacia el porvenir en una perspectiva amplia, universalista. Estos capítulos pueden ser considerados como la última composición profética de cierta consistencia, anterior a Daniel. Representan uno de los mejores ejemplos de reinterpretación y ulterior espiritualización de la precedente literatura profética mesiánico-escatológica ${ }^{3}$.

Su carácter oscuro y su contenido escatológico atrajo curiosamente la atención de los apocalípticos del judaísmo ulterior y sirvió frecuentemente a la primitiva comunidad cristiana de telón de fondo, de fuente inagotable de recurso, para situar en el marco de los planes divinos -motivación teológico-apologética- las enseñanzas y acontecimientos mesiánico-escatológicos de la vida de Jesús, de los que gran parte de sus miembros habían sido testigos. Se imponía a los predicadores de la Palabra mantener y exponer la continuidad histórica entre los sucesos que ellos proclamaban y la historia salvífica $o$ acción de Dios sobre Israel para demostrar que todos ellos estaban previstos o predichos por «Moisés y los Profetas» y, por tanto, constitulan el desarrollo lógico de la historia de Israel.

Especialmente se detecta el uso de Zac 9-14 en los relatos evangélicos de la pasión ${ }^{2}$ : entrada triunfal de Jesús en Jerusalén (Zac 9,

1. Cfr P. GRECH, "Interprophetic Re-interpretation and Old Testament Escathology": Augusíinianum 9 (1969) 253-254.

2. Cfr. B. LINDARS, New Testament Apologetic. The Doctrinal Significance of the Old Testament Quotations (London 1961) 110-111; Ch. 
9-10 = explícitamente citada en $\mathrm{Mt}$ 2I,5 y Jn I 2, I5 y con muchas alusiones en Mc I I, I-I I y Lc r9,29-48); referencia al templo como una casa de oración para todas las gentes y no como una casa de comercio $(\mathrm{Zac}$ 14,2I $=$ Mc II,15-17; Mt 21,12-13; Lc 19,45-46; In 2,16); posible alusión a la "sangre de la alianza" en la última Cena (Zac 9, I I $=$ Mc 14,24; Mt 26,28; Lc 22,20), ya que la fuente principal de referencia es Ex 24,8; predicción de la dispersión de los apóstoles (Zac I 3.7 $=$ Mc I 4,27; Mt 26,31); compra del campo del alfarero con el dinero de la traición de Judas $\left(\mathrm{Zac}_{\mathrm{a}}\right.$ 1,12-13 $=\mathrm{Mt}$ 27,9-10); transfixión del costado de Jesús (Zac 12, 10 $=$ Jn 19,37; cfr. Apoc 1,7$)$.

Numerosas son, además las alusiones o referencias explícitas a Zac 9-I4 que se dejan entrever en el Apocalipsis, cuarto evangelio, epístolas paulinas y literatura evangélica : la Jerusalén celestial o escatológica (Zac I 4,7-I I $=$ Apoc 1 I, I5; 22,3), la imagen del pastor inútil (Zac $11,15-17=$ Jn I0, I2-13), del buen pastor $(Z a c$ I 1,4-14 $=$ In Io,I-II,I 4-I8), la imagen de la oveja perdida y sin pastor (Zac1 1,16 = Mc 6,34; Mt 9, 36; 18, 12-13; Lc 15,3-7), la insistencia en la venida del Señor al son de trompeta junto con sus santos (Zac 9,I4; I4,5 = I Tes 4,I6; Mt I6,27;25,3I; 2 Tes 1,7$)$, etc.

Nuestro interés en el presente estudio se limita al uso e interpretación qué la liceratura bíblica neotestamentaria ha hecho de $\mathrm{Zac}$ 9,9-Io, oráculo profético de gran calibre, que anuncia la llegada a Sión de un Rey, victorioso y salvador, pero humilde, que destaca por su mansedumbre y actuación pacífica como características personales. Sin embargo, antes de adentrarnos en la interpretación neotestamentaria de este vaticinio, será de gran utilidad dedicar unas páginas al texto veterotestamentario y su reinterpretación intertestamentaria. Sólo así se podrá obtener una visión de conjunto e impostar la problemática mesiánico-escatológica, que dominaba el pensamiento de los tiempos de Cristo y de la Iglesia primitiva. También ésta, aunque en diversa escala, participaba de semejantes inquietudes y aprovechaba los elementos doctrinales útiles, que revoloteaban en el ambiente, para aplicarlos a Jesús.

H. DoDd, According to the Scriptures (London 1952) 64-67, 107: G. GatdE. Jerusalem, voici ton Roi. (Paris 1968) 174-189; F. F. BRuce, "The Book of Zechariah and the Passion Narrative": Bulletin of the John Rylands Library 43 (1960) 336-353. 
I. ZAC 9,9-10

Género literario y estructura:

Esta perícopa presenta claras analogías con los pasajes bíblicos de las (aclamaciones reales) (cfr Sal 2; 72; 1 10; Is 9.5-6; Sof 3,14r...), que suelen ir acompañadas de un oráculo en el que se promete al Rey de Sión el dominio universal. En ella se invita a Sión a desbordar de alegría ante la llegada de "su Rey", caracterizado como justo y salvador, que hace su entrada en la ciudad con medios arcaicos, como símbolos de la paz duradera que establecerá en su reino ${ }^{1}$

Literariamente -dos estrofas de tres miembros cada una- está construida en forma de paralelismo quiásmico, cuyo ritmo, simple y regular, tiende a resaltar, como punto céntrico el aspecto pacífico del Rey que llega ${ }^{2}$. Tal estructura quiásmica, resultante de un paralelismo de oposiciones y semejanzas, puede formularse más o menos así:

a) Jerusalén :

b) Rey Salvador:

c) montado sobre un asno:

c) supresión de caballos:

b') traerá la paz...:

a) toda la tierra:
«Exulta sin mesura, hija de Sión; lanza gritos de júbilo, hija de Jerusalén.

He aquí que tu Rey viene a tí, justo y salvado(r) él, humilde y montado sobre un asno, en un pollino, cria de asna.

El suprimirá los carros de Efrain y los caballos de Jerusalén;

será suprimido el arco de combate y él proclamará la paz a las naciones. $\mathrm{Su}$ dominio será de mar a mar y desde el Río hasta los confines de la tierra.

1. Cfr. G. Gaide, op. cit., 15-16.

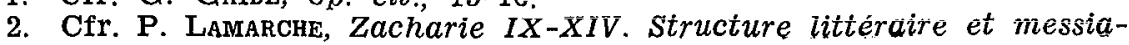
nisme (Paris 1961) 45; Th. ChaRY, Aggee - Zacharie - Malachie (Paris 1969) 162-163. 
Análisis del Texto ${ }^{3}$ :

Las invitaciones a la alegría (=exulta sin mensura: gîl; lanza gritos de júbilo: rûa') son típicas de los mensajes de salvación (cfr. Sof 3,14-17, Joel 2,20...) y recuerdan la designación del Rey de Israel (I Sam 10,24), la entronización del Rey mesiánico (Sal 2,I I; Is 9,2) o la celebración del reinado de Yahvé (Sal 89,16:97,1; 149,2; I Cron r6,31). Zac 9,9 ro parece evocar un contexto cultual de entronización de Yahvé o del Rey, fiesta en la que el pueblo rebosaba de júbilo *

El Rey que va a venir a Sión posee las cualidades de un buen rey. Es ante todo ( $j u s t o »$ ( $(a d \hat{\imath} q)$ ), justicia que se manifiesta tanto juzgando a sus súbditos con equidad como siendo justo a los ojos de Dios, esto es, fiel a la alianza y realizador de las condiciones de ésta en las relaciones de su pueblo hacia Yahvé (cfr I Sam 7, I5; 8,20; 2 Sam 8,$15 ; 15,4 ; 23,5$; Is II,I-5; 32,1-5; Jer 23,5; Sal 72...).

Es, además "salvado» (nôsha'), como quien permanece siempre bajo la protección de Yahvé y experimenta su auxilio (cfr Sal 18,2022; 20,10; 33,I6-I7; I I8,I4-I5...). Nĉsha', participio nifal de $y s h^{\prime}$, siempre que es usado en la Biblia - unas veinte veces- tiene un sentido pasivo o, al menos, reflexivo, acercándose más al significado de "ser salvado" que al de "salvador". Sin embargo, la mayor parte de las versiones, a causa de la personalidad de este rey y la referencia continuada de este pasaje al Mesías, han buscado un término que, conservando la idea del texto original, la expresara de modo menos chocante. ¿De qué o quiénes debía ser salvado el Mesías? Los LXX

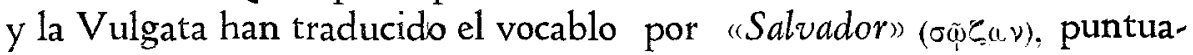
ción que representa ya una reinterpretación del texto deuterozacariano. Sin embargo, tal idea, tanto si es referida a Dios (cfr Is $45,15,2$ I; 2 Sam 22,42; Sal 18,42 ) como a los hombres ( $\mathrm{cfr}$ Is 19,20 ), suele expre-

3. Cfr. T. Jansma, "Inquiry into the Hebrew Text and the Ancient Versions of Zechariah IX-XIV": Oudtestamentische Studiën 7 (1950) 1142; M. SAEBo, Sacharja 9-14. Untersuchungen von Text und Form (WMANT) (Neukirchen 1969) 51-52; P. RiNaldi - F. Luciani, I Propheti minori: Michea - Nahum - Abacuc - Sofonia - Aggeo - Zacharia - Malachia (Torino 1969) 190-191; Th Chary, op. cit., 163-170.

4. Cfr. B.OTzeN, Studien über Deutero-Zacharja (Copenhaven. 1964) 135-136; K. ElifGER, Die Propheten: Nahum, Habakuk, Zephanja, Haggai, Zacharja, Maleachi (Göttingen - 1964) 149; Th. CHARY, op. cit., 163. 
sarse en hebreo mediante el participio hiphil (=mêshîa'). Por eso gran número de comentaristas y versiones modernas lo traducen por "victorioso mediante el auxilio de Yahvé» o simplemente "victorioso" ${ }^{5}$, que en parte conserva el fondo o matiz de "salvado" y sugiere el de "salvador». Sin embargo, no parece que haya razones suficientes para trastornar el sentido del texto original, ya que se apoya en bastantes lugares paralelos ${ }^{6}$.

Al mismo tiempo, es "afable, manso o humilde» ( $\pi$ paüc). Tal es el significado que han preferido dar al vocablo hebraico 'ânî (que esencialmente significa (affligido, miserable») la Versión de los LXX y la mayor parte de los traductores y comentaristas posteriores. En realidad es muy difícil dar aquí al vocablo su propio significado con todas sus consecuencias. Aunque los rasgos de "salvado) y "afligido" evocan discretamente la figura del Siervo de Yahvé, oprimido y sal. vado (cirr. Is 53,2-II), y preparan en cierto sentido la repulsa y opresión del Pastor de Yahvé (Zac ıо, 10; 13,7 ...), el carácter jubiloso del presente anuncio mesiánico y la descripción pacífica del Rey que se avecina a Sión invitan a preferir el sentido de (manso, afable o humilde», más pleno y significativo, que pueden englobar en sí los otros sentidos. Es muy posible que el Deutero-Zacarías haya escogido este vocablo por influencia de Sof 3,I I-I 8 (especialmente v. I2), oráculo con el que guarda muchos puntos de contacto y del que probablemente es una ulterior reinterpretación y escatologización ${ }^{7}$. De hecho el significado «manso, afable o humilde» será el que prevalecerá en el Nuevo Testamento (cfr. Mt I I,29; 21,5) al aplicar este vaticinio a Jesús.

El Rey que viene a Jerusalén hace su entrada pacíficamente: «montado sobre un asno, en un pollino, cria de asna) ${ }^{8}$. En la literatura bí-

5. Así, por ejemplo, Knabenbauer, Van Hoonacker, F. Zorell, P. Lamarche, Biblia de Jesusalén, Th. Chary, etc.

6. Cfr. G. Gaide, op. cit., 68; B. Otzen, op. cit, 137-138; M. Saebo, op. cit., $185-186$.

7. Sobre la significación exacta y la evolución semántica del vocablo 'ânî cfr. A. GeLIN, Les pauvres de Yahvé (Paris 1953) 30-52, 119-120; J. VAN DER PLOEG, "Les pauvres d'Israel et leur pieté": Oudtestamentische Studiën 7(1950) 236-270; Th. CHany, op. cit., 166-167.

8. Según Th. Chary, esta repetición no indica solamente un paralelismo sinonímico, sino una insistencia especial que deliberadamente trata de atraer la atención sobre la profecía mesiánica de Gen 49,11 (Op. cit., 168). 
blica el asno es un animal importante, que evoca la montura tradicional de los príncipes (cfr Jue 5,10; 10,4; 12,14) y reyes de Istael (crr. 2 Sam I8,9; I $\operatorname{Re} 1,33.3^{8.44)}$ y al mismo tiempo el texto de $\mathrm{Gn} 49$, I I, reconocido como profecía mesiánica misteriosa. En el presente contexto no solamente resalta la humildad del Rey que viene, sino también su aspecto pacífico, en oposición al equipaje de los reyes impíos y conquistadores af́anosos, rodeados de caballos y carros de combate (cfr Zac 9,10; 10,5; Jer 17,25; 22,4; I Mac I,I7; 3,39; 2 Mac 9,4...).

A su actitud pacífica al ingreso en la capital del reino, añade el profeta todo un programa y mensaje de paz, que el Rey viene a desarrollar no solamente dentro de los confines de las tribus de Israel (= Efraim-Jerusalén), sino incluso entre las naciones en general: "suprimirá - mientras en el TM el sujeto es Yahvé: "yo suprimiré», los LXX y la peshita armonizan el inicio y el final del v. Io, poniendo el verbo en tercera persona y obteniendo así un sentido mejor - los carros de Efraim y los caballos de Jerusalén, rectificando discretamente los aspectos negativos, bélicos, del reinado de Salomón (cfr I Rey $5,6 ; 9,19 ; 10,26-29 .$.$) , en el que tal vez se ha inspirado el profeta$ postexílico.

Ejercerá, además, su dominio universal no mediante las armas - (el arco de combate) es una metonimia para designar todas las armas bélicas - sino proclamando la paz a las naciones ${ }^{10}$. No se trata simplemente de cesación de hostilidades o de imposición de condiciones de paz en virtud de una victoria, sino más bien de aportación y ofrecimiento de paz y prosperidad en el sentido más amplio (cfr Zac 8, 12: Sal 122,6-8). Como en Is I I,4 el cetro se convertía en (cla vara de su boca), aquí el "señorío de paz) se convierte en "anuncio de paz". Curioso es - y un tanto inexplicable - el texto de los LXX al traducir la última sentencia "y proclamará la paz a las naciones" : $x \alpha i \pi \lambda \dot{y}_{\text {- }}$

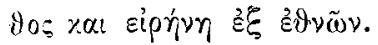

El dominio universal y pacífico del Rey mesiánico está expresado mediante una indicación poética que, sobrepasando los límites rea-

9. Cfr. J. SPERBer, "Der Personenwechsel in der Bibel": Zeitschrift für Assyriologie und verwandte Gebiete, 32 (1918) 23-33.

10. Cfr. M. Descor, "La Paix et le Messie juif, nouveau Salomon en Zacharie 9, 10". Congreso Eucarístico Internacional I (Barcelona 1954) 331-334; A. Skrinjar, "Messias rex pacificus": Verbum Domini 12 (1932) 248-253. 
les del reino en tiempos de Salomón (cfr. I $\operatorname{Re} 5,4 ; 2$ Cron 7,8) y los confines ideales de la Palestina (cfr. Gen I5,18; Ex 23,23.3 I; Sal 8o, I2), abarca toda la tierra: "su dominación se extenderá de mar a mar (= Mediterráneo-Rojo) y desde el Río (= Eufrates) hasta los confines (sur) de la tierra" (cfr. además, Sal 72,8; Zac 14,9). El Rey que viene a Sión será quien aporte y brinde a toda la tierra los beneficios y la salvación escatológica.

\section{Interpretación :}

La mayor parte de los comentaristas -mor no decir todos- han visto en este oráculo del Deutero-Zacarías la descripción de un Rey mesiánico, enteramente disociado de la persona de Zorobabel ${ }^{11}$. Lo sugieren, además de la invitación a la alegría, el título de Rey y su justicia, las restantes imágenes, características del reino mesiánico: abolición de instrumentos de guerra (cfr. Os 1,7 ; 2,18-20; Is 2,4; Miq. 4,3 ; 5,9-13), el retorno de Efraim o Israel al seno del reino de Judá (cfr. Jer 3,6-13; 3, $18-20$ ) y las dimensiones de este reino mesiánico (cfr. Sal 72,8).

Tal descripción, sin embargo, yuxtapone dos concepciones completamente opuestas, sin intentar resolver su antagonismo. Por una parte contiene ciertos elementos arcaicos, fruto problable de una idealización del Rey justo y sabio, cuya imagen más perfecta estaba encarnada en la persona de Salomón, hijo de David, cuyo solo nombre era ya un presagio de paz (cfr. 2 Sam $7=$ I Crón I7; I $\operatorname{Re~I,38-40;~}$ 5,I-4; Sal 72; Is 9,I-6...). Por otra parte, algunos rasgos del Rey que viene a Sión, tales como su mansedumbre-humildad o aflicción-opresión, revelan una concepción completamente reversa, que evoca una ideología relativamente tardía, cuyas raíces descienden hasta la figura del Siervo sufriente (Is 42, I-4;53, I-I 2; Sal 22).

Con esta mezcla de elementos arcaicos y tardíos -oráculo que reinterpreta y entrelaza los textos mesiánicos precedentes en una unidad de visión ${ }^{12}$ - el profeta deja entrever una concepción profun-

11. Cfr. P: Lamarche, op. cit., 16,45 .

12. Cfr. P. GRECH, "Interprophetic Re-interpretation".., 253-254; K. Filiger, op. cit., 150; M. DELCOR, "Les sources du Deutero-Zacharie et ses 
dísima del Mesías en el ideal religioso de los (anawim», que suministrará a los escritores neotestamentarios el fondo doctrinal de su imagen de Jesús como Mesías humilde en el molde de la terminología tradicional, capaz de despertar entre sus lectores el recuerdo y las aspiraciones mesiánicas, ahora cumplidas en la persona de Jesús. La fe del profeta, como la de los evangelistas, no teme proponer la paradoja de un rey humilde dominando sobre el mundo entero. Se trata ciertamente de un rey, pero prácticamente está desprovisto y despojado de todo atributo real y político.

II. INTERPRETACIÓN INTERTESTAMENTARIA DE ZAC 9,9-10.

La Versión de los LXX:

Como se anotó anteriormente ${ }^{1}$, la Versión de los LXX representa ya la primera reinterpretación de Zac 9,9-10. La traducción de

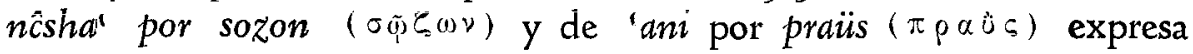
más directamente la humillación en la victoria, es decir, la idea de un Rey victorioso que se presenta en actitud mansa, afable y sencilla, que la humillación y opresión-aflicción a la que sigue el triunfo, bajo la protección de Yahvé ${ }^{2}$. Sin negar la posibilidad de que tal traducción haya podido estar influida por Is 45,2 I donde se encuentran conjun-

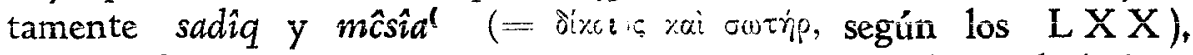
$y$ por Sof 3,I I-I 8 , que se asemeja a Zac 9,9-1o en el vocabulario y contenido, tal vez no sea ajena a los traductores una motivación teológico-apologética: apropiación de alguncs rasgos de Yahvé al Rey mesiánico y ansia de presentar a las masas paganas, en cuyo ambiente

procédés d'emprunt": Revue Biblique 59 (1952) 385-411: W. H. Schmidt, "Die Ohnmacht des Messias. Zur Ueberlieferung des messianische Weissagungen in A. Testament": Kerigma und Dogma 15 (1969) 18-34; P. GRELor, Sens chétien de l' Ancient Testament (Tournai 1962) 375-376.

1. Cfr. p. 4 ss.

2. Cfr. R. F. Fuller, The Foundations of New Testament Christology (London 1965) 28. 
se desarrollaba la vida de la comunidad judía de la Diáspora, una imagen y personalidad más atractiva del Rey mesiánico. Su justicia, poder salvador y pacifismo favo:ecerían sin duda el proselitismo mucho más que la imagen de un Mesías op:imide, rrisione: y miserable.

\section{Literatura apócrifa}

En la literatura apócrifa Zac 9,9- Io no parece haber tenido mayor resonancia; prácticamente no se da referencia alguna, ni siquiera implícita, a este oráculo ${ }^{3}$. Las posibles referencias o semejanzas de vocabulario y de pensamiento son más aparentes que reales; suele tratarse de temas comunes en la literatura bíblica.

En el Libro de Enoch $(52,8)$ se recuerda la eliminación de los elementos de los que derivan los instrumentos de la guerra: hierro, bronce, plomo...; serán inútiles y por nadie ya estimados ". Es tema frecuente en la literatura profética (cfr. Is 2,$4 ; 9,4 ; \mathrm{Ez}$ 39,9,9-10; Os 2,20 ) y en los cantos litúrgicos (Sal 46, ro...).

En el Testamento de Judá $(24, \mathrm{I}-6)$ se anuncia la venida en paz de "la estrella de Jacob y del sol de justicia — se discute si la expresión corresponde a la tribu de Judá o a la de Leví - caminando con los hijos de los hombres en mansedumbre y justicia, en el que no se encontrará pecado» (V.I), imagen del Mesías que en algunos rasgos es esencialmente paralela a la descrita en Zac 9,9-10. Sin embargo, estas cualidades eminentes asignadas a la cestrella que se levantará de Jacob) evocan también el bello poema mesiánico de Is $\mathrm{I}, \mathrm{I}, \mathrm{I}-\mathrm{IO}$ ( $\mathrm{cfr}$ además, 9,6; Sal 45,4-7), al que se alude directamente en los vv. 56: (entonces resplandecerá el cetro de mi reino y de mi tronco saldrá un vástago, del que crecerá una vara de justicia para los gentiles, para juzgar y salvar a todo el que invoque al Señor» ${ }^{5}$.

En los Salmos de Salomón $(\mathrm{I} 7,23-45)$, la más clásica expresión

3. Cfr. H. L. STRACK - P. Bthlerbeck, Kommentar zum $N$ Testament aus Talmud und Midrasch, I, 842.

4. Cf:- F. Martin, Le Livre d' Henoch (Paris 1906) 107; R. H.CHARLEs, The Apocrypha and Pseudepigrapha of the old Testament in English, II, (Oxford 1913) 219; E. KaUTSCH, Die Apocrypha und Pseudepigrapha des Alten Testament $I I$ (Tübingen 1900) 266.

5. Cfr. M. DE JoNGE, The Testament of the Twelve Patriarchs. A Stu$d y$ of their Text, Composition and Origin (Manchester 1953) 89ss; R. C. Charles, op; cit., II, 323-324; E. KaUTsCH, op. cit., II, 477. 
de expectación mesiánica espiritualizada predominante en los tiempos neotestamentarics ${ }^{6}$, "el Mesías Rey, hijo de David, que Dios suscitará sobre Israel (v.23), estará dotado de sabiduría y de justicia (v.26), mediante las cuales gobernará con rectitud al pueblo santo, las doce tribus del pueblo santificado por el Señor, su Dios (v.28). Juzgará a las naciones con la sabiduría de su justicia (v.3I) y hará que los pueblos paganos le sirvan bajo su yugo (v.32). Tal es el Rey justo, instruido por Dios (v.35), el Cristo o Mesías (v.36). No confiará en el caballo, en el caballero o en el arco, ni acumulará oro ni plata para la guerra, ni reunirá un ejército, la esperanza para el día de la guerra (v. 37). El Señor, a quien está sometido, es su Rey, su esperanza; será todopoderoso por su esperanza en Dios (v. $38 \mathrm{a})$; tendrá piedad de todas las naciones con temor ante $\mathrm{El}\left(\mathrm{v} .3^{8 \mathrm{~b}}\right)$, pues reducirá la tierra por la palabra de su boca para siempre (v. 39). Bendecirá al pueblo del Sefícr con la sabiduría, con el gozo (v. 40), destruirá los pecadores por la fuerza de su palabra... (v. 4I). Dios le hará poderoso por el espíritu santo. y sabio por el don de entendimiento, acompañado del poder y de la justicia....) (v. 42).

Realmente tal descripción se avecina sobremanera a la imagen del Rey mesiánico de Zac 9,9-1o y al Cristo de los evangelios. Sin embargo, entremezcladas con estas notas altamente espiritualistas se descubren también características que enfatizan el aspecto político y nacionalista del futuro Mesías, concepción común en los escritos intertestamentarios: "estará ceñido de fuerza para aniquilar los príncipes injustos (v. 24); purificará Jerusalén de las naciones paganas, que la pisotean, destruyéndolas ( $v .25)$, de modo que expulsará violentamente a los pecadores de la heredad; quebrantará el orgullo de los pecadores, como vasos de alfarero; destruirá con vara de hierro toda su sustancia (v. 26). Destruirá las naciones impías con la palabra de su boca, de modo que, ante su amenaza, los paganos huirán velozmente lejos de su vista (v. 27); el emigrante y el extranjero no morarán entre ellos, pues juzgará a los pueblos con la sabiduría de su justicia... (v, $3 \mathrm{r})$. Estará libre de pecado para regir los pueblos numerosos y remover los pecadores por la fuerza de su palabra...»? 324.

6. Crr. J KLausnLR, The Messianic Idea in Israel (London 1956) 323-

7. Cfr. J. Viteau - F. Martin, Les Psalmes de Salomon, (Paris 1911) 351-369; R. H. ChaRLeS, op. cit., II, 649-651; E. KAUTSCH, op. cit., II, 146-148. 
El ideal de perfección religiosa y moral que el Mesías davídico encarna en este escrito de tendencia farisaica, tampoco pierde de vista el plan terrestre, nacionalista, del pueblo judío. Por otra parte, las semejanzas temáticas con Zac 9,9-10 se difuminan vanamente hasta resultar un tanto efímeras. La tradición seguida por el autor de los Salmos de Salomón revela predominantemente un fondo doctrinal isayano y litúrgico (cfr. Is 2,2-4; 9,5-6; II,I-II; 45,I3-I 7 ..; Sal $9,8.20 ; 63,5 ; 72$; Deut $17,16-17 \ldots)$.

\section{Literatura qumránica:}

En los escritos de Qumrâm el uso de Zac 9,9-1o prácticamente carece de importancia. Solamente una vez, en la tercera estrofa del Himno de entusiasmo (Regla de la Guerra, col XII, lín'ea 13), se hace alusión al oráculo profético. El autor recoge la interpelación del profeta a Sión o Jerusalén -que él extiende a las villas de Judá y a las hijas del pueblo- invitándolas a la alegría ante la victoria del Hijo de la Luz, personificado bajo los trazos de un guerrero valeroso, que vencerá a los paganos con sus reyes a la cabeza y hará entrar cautivos en Jerusalén. Sin embargo, se trata simplemente del uso de expresiones y temas familiares entre los escritores judaicos - combinación del Sal 4,I2 (ó 97,8) con Zac 9,9-10- ya que la imagen del Héroe o Hijo de la Luz y su acción belicosa son la más completa antinomia del Rey manso y pacífico de Zac 9+9-10 ${ }^{8}$.

\section{Literatura rabinica:}

Con singular unanimidad, el Talmud y las antiguas autoridades rabinicas han aplicado siempre el vaticinio de Zac 9,9-10 al Mesías ${ }^{9}$.

8. Cfr. J. Carmignac - P. Guibert, Les textes de Qumrôn traduits et annotés (Paris 1961) 113, nota 76; J. Carmignac, La Régle de la Guerre (Paris 1958) 183; J. MaIXr, Die Texte von Toten Meer, I (München 1960) 148; M. Burrows, The Dead Sea Scrolls (New York 1956) 398.

9. Cfr. A. EDERSHerm, The Life and Times of Jesus Messiah II (London 1907; 370; Strack-Billerbeck, op. cit., I, 842. 
Especialmente la imagen del Mesías montado en un asno aparece con diversos matices y aplicaciones y deviene intencionalmente un tema obligado entre los signos que anuncian su venida.

Conviene primeramente señalar la insistencia con que los rabinos relacionan al "Mesías montado en un asno" con los grandes personajes de Israel, Ábraham, Jacob, Moisés..., y con la misión por éstos desempeñada en la prehistoria y formación del pueblo elegido: como el "(padre» y el primer "salvador" de Israel, así también el último salvador o Mesías ${ }^{10}$. Tales referencias testimonian ya el interés de los escritores judáicos en resaltar la continuación de los planes divinos en la historia salvífica del pueblo elegido.

Dentro de esta perspectiva histórico-salvífica es preciso incluir la interpretación mesiánica de Gén 49, I I, oráculo que, incluso en opidel vocablo, insistiendo en que el Rey Mesiánico de Zac 9,9 no es nión de algunos autores modernos ${ }^{11}$, tiene en Zac 9,9-y tal vez en Mt 21,2.5·7- su más perfecta reinterpretación y ulterior especificación. De este modo la profecía de Jacob adquiere en la tradición rabínica un sentido profundo, cual anuncio velado de un rey judío, que do-

10. En Peshiktha Rabbathi, 34 (159b) es interpretado asi Zac 9, 9-10: "a causa de los impios, que no tienen recompensa alguna, se presenta 'montado en un asno' y recuerda - con su montar sobre el asno- el premio de los patriarcas, especialmente de Abrahám, que, obedeciendo al precepto de Dios, se puso en marcha y aparejó por si mismo el asno..., conforme a Gen 22, 3".

En Pirqe Rabbi Eliezer 31, se lee refiriéndose a Gn 22,3: "éste era el asno sobre el que montó Moisés cuando partió para Egipto (Ex 4,20), y éste será el asno sobre el que montará el Hijo de David (=Mesias), según Zac 9, 9".

En Midrash Qohelet 1, 9 (9b) se conserva esta sentencia del Rabbí Berekja (=hacia el 340 d. C.), recogida del Rabbí Jischaq (hacia el 300 d. C.): "como el primer salvador (=Moisés), asi también el último salvador (=Mesias). Y comparaba Ex 4, 20 con $\mathrm{Zac} 9,9$. El mismo rensamiento se transmite en Midrash $\mathrm{Sm}$. 14, 9 (45b) de labios del Rabbí Levi (=hacia el 300 d. C.).

En Genesis Rabba 75 (48c), teniendo en cuenta Zac 9, 9, los rabinos (hacia el 150 d. C.) interp etaban -interesante lección de exégesis- los "asnos" que poseía Jacob (Gén 32, 6) como referencia al Mesías hijo de David, mientras que las "bestias" de Jacob (Gén 32,6) eran referidas al Mesías hijo de José o de Efraim, aludiendo a Deut 33,17.

Cfr. Strack-bIlerbeck, op. cit., I, 842-844; O. MICHEL, ivos, Theologisches Wörterbuch zum Neuen Testament V, 284-285..

11. Cfr. Th. Chary, op. cit., 168; J. Blenkinsopp, "The Oracle of Juda and the Messianic Entry": Journal of Biblical Literature 80 (1961) 55-64. 
minará toda la tierra ${ }^{12}$. El asno y la viña de Soreq se convierten así en signos positivos de la venida del Mesías y de la salvación escatológica ${ }^{13}$.

En la línea de las señales que acompañarán la venida del Mesías debe colocarse también la interpretación del Rabbí Jehosuah Ben Leví (= hacia el $25^{\circ} \mathrm{d}$. C.), uno de los grandes y estimados maestros de la Haggadah. Armonizando Zac 9,9 con Dan 7,9-14, interpretado individualmente en el convencional sentido mesiánico, comentaba: “si los israelitas son dignos, el Mesías vendrá en las nubes del cielo; pero, si son indignos, vendrá humilde y montado en un pollinom ${ }^{14}$. Evidentemente la explicación representa una concepción peyorativa, un tanto desfavorable ${ }^{15}$, del equipo de montura en que, según Zac 9,9-10, el Rey mesiánico hará su entrada en la ciudad de Sión. Tal concepción será aprovechada por Mateo para poner de relieve, por motivaciones apologéticas, la indignidad y culpa del pueblo judío al rehusar aceptar a Jesús, su Rey.

La ambigüedad que reinaba en las versiones al traducir el vocablo nôsha' de Zac 9,9, se advierte también en el Targum Palestinense y en la literatura rabínica. Mientras aquél ${ }^{16}$ describe al Mesías como un salvador o (libertador), traduciendo nôsh $a^{\prime}$ por perîq, en la literatura rabínica expresamente se rectifica un posible malentendido del vocablo, insistiendo en que el Rey mesiánico de Zac 9,9 no es

12. En Genesis Rabba 98 (62a) se anota que los rabinos (hacia el 150 d. C.) interpretaban mesiánicamente Gen 49,11 con relación a Zac 9,9, diciendo: "Yo ( $=$ Dios) estoy unido a la viña (=Israel) y a la cepa de su ciudad (=Jerusalén), cuando venga el Mesías montado sobre un pollino (=su borriquillo), como dice Zac 9,9,: pobre y montado sobre un pollino..." Cfr Strack-BILlerbeck, op. cit., I, 842-843.

13. Eñ Beraktoth 56̂́, 57a se lee: "aquel que ve en sueños un asno o una viña de Soreq, puede esperar al Mesías y su salvación, conforme a Zac 9,9 y Gen 49,11". Cfr. Strack-Billerbeck, op. cit., I, 843; J. Bonsirven, Le Judaisme palestinien au temps du Christ I,, (Paris 1934), 392.

14. En Sanedrin 98a. Cfr. STrack-BIllerbeck, op. cit., I, 843; M. J. LAGRANGE, Le Messianisme chez les Juifs. (Paris 1909) 227-228; G. F. Moore, Iudaism in the first Centuries of the christian Era II (Cambridge, Massachusetts 1962) 334-335; S. MowINCKEL, He that cometh (Oxford 1959) 336.

15. Eco de este matiz desfavorable es la anécdota que recuerda cómo el rey Schabor decía a Schemuel ( $\dagger$ 254): "vosotros decís cue el Mesias vendrá sobre un pollino; yo quiero enviarle un reluciente caballo blanco, como yo lo poseo". Y le contestó: “¿tienes tú uno de mil colo es?". Pues sir pollino debería ser de mil colores. Cfr. STRack-Billerbeck, op. cit., I, 843. 
llamado "(salvador), sino (cuno a quien se salvará)" ${ }^{17}$. Una armonización de ambas perspectivas aparece en Peshiktha Rabbathi. En una curicsa parálrasis sobre Zac 9,9, el Mesías es denominado (justo y salvador», pero también "salvado" pues será humillado durante años en la prisión y será causa de mofa para los impíos de Israel ${ }^{18}$. Tal tradición, sin embargo, no parece haber ejercido influencia alguna negativa respecto a la imagen del Mesías como libertador triunfante y glorioso.

Por último, en la literatura rabínica se destaca el papel pacificador del Mesías - (paz) es uno de tantos títulos raros con que se le designa ${ }^{19}$ - como uno de los grandes beneficios para los tiempos de la consumación. Sin embargo, es más bien la tradición bíblica isayana (Is 9,$5 ; 52,7)$ la que aporta el soporte para tal denominación. Sólo en Tanchuma Shophethim se hace una pequeña referencia al programa de paz que el Mesías aportará a las naciones y la universalidad de su reino, aludiendo a $\mathrm{Zac} 9,9-10^{20}$.

16. Cfr. R. LE DEAUT, La nuit pascale (Roma 1962) 278.

17. En Tanchuma ahare Môth 18 (36a) se conserva lo que decía el Rabbí Berehhja (=hacia el 340 d. C.): "mira lo que está escrito en Zac 9,9: 'salta de gozo, hija de Jerusalén..., él es justo y uno a quien se salvará'. No es llamado 'el que salva', sino 'el que será salvado". Eil mismo pensamiento, más ampliamente expuesto, aparece en Exodus Rabba 30 (91b). Cfr. Strack-Billerbeck, op. cit., I, 844.

18. Peshiktha Rabbathi 34 (159b): "El es justo y salvador" (Zac 9,9): éste es el Mesías, pues sentenciará justamente el juicio sob-e Israel, cuando se mofaba o reía de él, estando en la prisión, por lo que es denominado justo. ¿Por qué se llama "salvador?". Cuando él, como justo, haya notificado el juicio fallado sobre ellos, les dirá: ¿acaso no sois todos vosotros mis hijos?". Ciertamente todos vosotros experimentaréis la salvación por la misericordia de Dios. "Manso y humilde, montado sobre un asno": éste es el Mesías. ¿Po: qué manso, humilde? Porque él todos aquellos años será humillado en la prisión y los impios de Israel se reirán de él. "Montado en un asno", a causa de los ímpios, que ninguna recompensa merecen..." Cfr. STrack-BILlerbeck, op. cit., I, 844.

19. "La paz -decia el Rabbí José Hagelili (=hacia el 110 d. C.) es un gran bien; cuando venga el Rey, el Mesías y se manifieste a Israel, aparecerá como pacífico: "que preciosas en la montaña las huellas del mensajero que anuncia la paz" (Is 52,7). Cfr. STrack-BILLERbeck, op. cit., III, 585; J. BoNsirven, op. cit., 365, 443.

20. En Tanchuma Shophetim (19a) se lee: "cuando te aproximes a una ciudad para luchar contra ella, invítala a la paz, según Deut 20,10. La Escritura habla del Rey, del Mesías, que se mostrará pacíficamente con ellos (=las naciones), como está escrito: "él ofrecerá la paz a las gentes -gojim- y su reino se extenderá de mar a mar" (Zac 9,10). Cfr. STRACK-BILleRBEcK, op. cit., III, 148; J. Bonsirven, op. cit., 443. 
III. INTERPRETACION NEOTESTAMENTARIA EN ZAC 9,9-IO

A) Citas o alusiones a Zac 9,9-10 en el Nuevo Testamento.

Los escritores neotestamentarios se han detenido profusamente en el contenido de este oráculo - referido tradicionalmente al Mesías - cuya descripción presentaba tantas analogías con los hechos de la vida de Jesús o con sus palabras. De manera especial ha sido explotado por la tradición evangélica para ilustrar su propia teología sobre la persona de Jesús y su reinado mesiánico. Las citas de reflexión y las alusiones que en el Nuevo Testamento responden a la temática de Zac 9,9-1 o son las siguientes:

a) La venida a Sión de un rey, humilde y pacífico, montado sobre el pollino de un asna, es explícitamente citada y aplicada a la entrada de Jesús en Jerusalén en Mt 21,5 y Jn I2, I5 e implícitamente supuesta - con diversos contactos literarios- en Mc I I, I-I I y Lc I9, $29-40$.

b) La mansedumbre y humildad, características del Rey mesiánico en Zac 9,9-10, son asignadas en Mt I I,29 a la persona de Jesús.

c) Los temas mesiánicos de la alegría ante la llegada de un Rey salvador son implícitamente recogidos y presentados en Lc $1,28-35$, al anunciar por boca del ángel la concepción y nacimiento de Jesús.

d) La misión y actuación pacífica del Rey mesiánico de Zac 9, 9- Io es apropiada frecuentemente a Jesús - tal vez sin relación directa con el texto deuterozacariano- mensajero y portador de la paz a Israel y a las naciones, especialmente en los escritos lucanos (Lc I,79; 2,14; 19.38.41; Act 10,36) y en algunas epístolas paulinas (Ef 2, 14. i7) en las que la paz deviene un atributo o calificativo con el que se designa al Señor (cfr I Tes 5,23; 2 Tes 3, I6; I Cor I 4,33; 2 Cor I3,II; Rom 15.33; Fil 4,9); Juan, por su parte, describe a Jesús ofreciendo "su paz» a los discípulos (14,27; 20,19.2 I).

B) Zac 9,9-1 o y los relatos evangélicos de la entrada triunfal de Jerusalén (Mc I I, I-I I ; Mt 21,I-17; Lc 19,29-38; In 12,12-16).

Les relatos evangélicos de la entrada triunfal de Jesús en Jerusalén, revividos litúrgicamente cada año por el pueblo cristiano con 
la Procesión del Domingo de Ramos, contienen en mayor o menor escala citas y alusiones a varios textos veterotestamentarios entre los que ocupa un lugar destacado el oráculo de Zac 9,9-1o. Con la utilización de este vaticinio se abre la serie de textos deuterozacarianos (Zac 9-14) reincorporados y actualizados más o menos explícitamente por los evangelistas en los relatos de la pasión. Sin duda el motivo fundamental que alienta en los escritores evangélicos tal inserción es dar un mayor énfasis al significado mesiánico de los últimos acontecimientos de la vida terrestre de Jesús. El cumplimiento de los vaticinios proféticos en la persona de Jesús invitaba a los primitivos cristianos a situar tales acontecimientos dentro de los designios de Dios, buscando, además, su sentido teológico.

Dado que cada evangelista alude o reincorpora diversamente en su narración el oráculo mesiánico de Zac 9,9-1o, se impone el estudio por separado de cada relato en concreto. Solo así será posible enmarcar debidamente el texto veterotestamentario en la teología y labor redaccional de cada evangelista y clarificar el sentido y la perspectiva en que se orienta la perícopa de la entrada triunfal de Jesús en Jerusalén.

$$
\text { 1) Zac 9, 9-10-Mt 21, I-I7 }
$$

Importancia de esta cita de reflexión en $M t$ 2I, I-I7

Una cita explícita de Zac 9,9 se encuentra en Mt 21,5, introducida mediante la típica expresión mateana "para que se cumpliera el oráculo del profeta) (Cfr I,22; 2,5.15.17.23; 3,3; 4,14; 8,17; $13,35 ; 27,9)$. Su importancia es tal que prácticamente de ella depende y a ella se acomoda toda la configuración o estructuración del relato ${ }^{1}$.

1. En diversa escala este mismo fenómeno se registra en Mt 1,18-25 4,12-17; 8,2-17; 27,1-10. Cfr. J. J. O'RouRKe, "The Fulfiment Text in Mt": The Catholic Biblical Quarterly 24 (1962) 395-397; N. WaLKER, The Alleged Matthean Errata: New Testament Studies 9 (1963/64) 392-393; G. STRECKER, Der Weg der Gerechtigkeit. Untersuchung zur Theologie des Matthäus (Göttingen 1966) 51-85; G. BorNkaMan - G. BarTh - H.J. HELD, Ueberlieferung und Auslegung im Matthäus-Evangelium (WMaNT) (Neukirchen 1965), 117-122. 
Siguiendo el esquema veterotestamentario de (orden-ejecución), en el que la palabra de Yahvé se revela como creadora o conductora de la historia o de la $\mathrm{fe}^{2}$, la cita de reflexión de Zac 9,9 estilísticamente aparece en el centro de la primera parte de la perícopa (vv. I-7), dividiéndola así en tres partes bien delimitadas: orden o mandato (vv, I-3), cita de reflexión (vv, 4-5), ejecución del mandato (vv, 6-7). Tal esquema es frecuente en Mateo ${ }^{3}$.

Por ctra parte, la cita bíblica aducida por el evangelista no corresponde exactamente en su puntuación con el texto del oráculo deuterozacariano, sea según los LXX, sea según el TM *. Mateo añade o suprime algunas expresiones que, conforme a su perspectiva teológica, delimitan exactamente el retrato de Jesús de antemano preconcebido en su mente y preparan en cierto sentido el resto del relato: aclamación y testimonio de la muchedumbre a la turbada ciudad de Jerusalén (vv. 8-II), acogida fría de los representantes de Israel a su Rey davídico (vv, I2-I 7). Incluso llega a duplicar las bestias de montura - probablemente por un incomprendido paralelismo del texto de Zac $9,9^{5}$ - y a hacer montar a Jesús sobre ambas a la vez (vv.

2. Cfr. Ex 7,1-6.8-10.19.20... ; Lev 8,1-5; 24,13-23; Núm 8,1-4; etc.

3. Cfr. $1,18-25 ; 2,13-15.19-23 ; 26,17-19 ; 28,12-15$. La forma literaria de este esquema ha sido ampliamente estudiada, tanto en el aspecto literario como en el teológico, por R. PESCH, "Eine Alttestamentliche Ausführungsformel im Niatthäusevangelium. Redaktionsgeschichtliche und exegetische Beobachtungen": Biblische Zeitschrift 10 (1966) 220-245; 11 (1967) 79-94.

4. Cfr. F. F. BRuce, "The Book of Zechariah and the Passion Narrative": Bulletin of the John Rylands Library 43 (1960/61) 339.

5. La mayor parte de los comentaristas coinciden en esta afirmación. Así, por ej., P. BonNard, L'Evangile selon Saint Matthieu (Neuchâtel 1963) 303; W. Grundmann, Das Evangelium nach Matthäus (Berlin 1968) 148; J. C. Fenton, Saint Matthew (London 1963) 330; O. Miched, Loc. cit. 286; D.

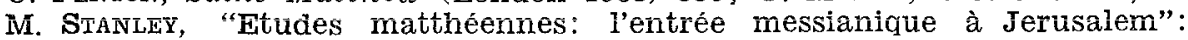
Sciences Ecclesiastiques 6 (1954) 103-106; P. NEPPER-ChrISTENTEN, Das Matthäusevangelium, ein judenchristliches Evangelium? (Aarhus 1958) 145149 , etc.

Otros, sin embargo, niegan este malentendido paralelismo, incomprensible en un escritor semita o, al menos, buen conocedor del ambiente y de la literatura judia, mostrando que el evangelista no introduce el asna o madre del pollino por ignorar el paralelismo de los miembros -que claramente es conservado en la cita: v. 5 - sino para resaltar más el hecho de que el pollino, como afirma Marcos $(11,2)$, aún no habia sido montado por hombre alguno, ya que no había sido separado de su madre. Asi, v. gr. B. Lindars, New Testament Apologetic (London 1961) 114; R. H. GuNDRY, The Use of the Old Testament in St. Matthew's Gospel with special Reference to the Messianic Hope (Leiden 1967) 197-199. Por otra parte, K. 
2.7). Este modo de reinterpretar los vaticinios proféticos ilustra de algún modo el midrash (peser) utilizado en la Iglesia primitiva al actualizarlos en Jesús.

Análisis y comparación de textos.

Una mirada comparativa entre Mt 21,5 y Zac 9,9 pone eñ evidencia el trabajo redaccional de Mateo en la cita de reflexión:

$$
\text { Mat } 21,5 \quad \text { (TM) Is 62,II } \quad(\mathrm{LXX})
$$

Decid (zi' $\pi \alpha \tau \varepsilon)$

a la hija de Sión

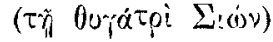

He aquí que : (iסoj)

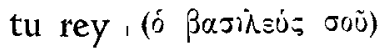

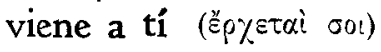

('imerû) Decid (är $\alpha \tau \varepsilon)$

a la hija de Sión

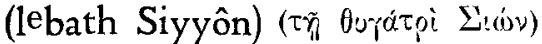

(TM) Zac 9.9 (LXX)

(hinneh) He aquí que ((iòoi)

(malkek) tu rev (is $\left.\beta a s i \lambda \equiv \delta^{\circ} \sigma \sigma, j\right)$

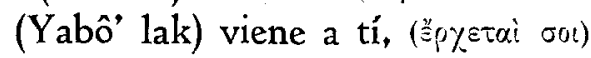
justo y salvador él,

manso ( $\pi \rho \alpha \dot{b} s$ ) ('anî) manso $\left(\pi \rho \alpha \dot{s}_{5}\right)$

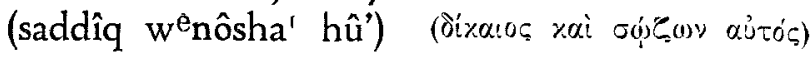

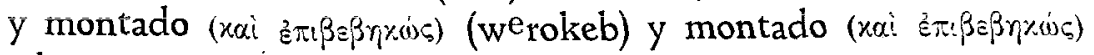

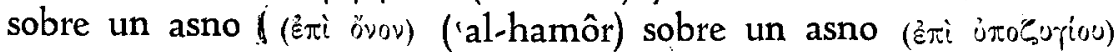

y sobre un pollino

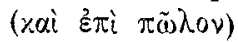

en un pollino

hijo de un animal de yugo

$\mathrm{w}^{\mathrm{èl}} \mathrm{al}$ ' ayir) ( $(\alpha \div: \pi \tilde{\omega} \lambda$ ov)

(viòy unósuriou)

cría de asna

(ben-'athonôth) (vธs(y)

Curiosamente se advierte que Mateo introduce la cita de reflexión de Zac 9,9 con un encabezamiento, tomado de Is 62, I I. La introducción de $\mathrm{Zac}$ 9,9 en este caso no se adaptaba al contexto teoló-

Stendhal, The School of St Matthew and its Use of the Old Testament (ASNU) (Uppsala 1954) 200, reconoce esta razón como secundaria $\mathrm{y}$ hace derivar el duplicado de bestias de montura de una tradición rabinica, si bien desconocida (Ibid. 119, 200-201). Cfr. R. S. McCoNNELL, Law and Prophecy in Matthew Gospel (Basel 1969) 127-128; J. W. Rothruchs, Die Erfüllungszitate des Matthäus-Evangeliums (BWANT) (Stuttgart 1969) 81-82, quienes recogen y resumen todas las hipótesis sobre el tema. 
gico, ya que la ciudad de Jerusalén reacciona diversamente (vv.10.15) $y$ en realidad no participa en la alegría ${ }^{6} ;$ sin embargo, la cita de Isaías presenta esta entrada de Jesús como un anuncio regio y salvador para la ciudad de Jerusalén, de la que se espera una reacción o respuesta comprometida.

Curiosa y sorprendente en extremo resulta también la omisión

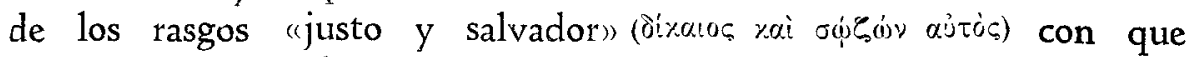
en Zac 9.9 queda caracterizado el Rey mesiánico. Tales aspectos están perfectamente de acuerdo con el retrato mateano de Jesús como Mesías- (salvador): I,2I; (justo» y cumplidor de toda justicia: 3,$15 ; 5,17 ; 27,19.24-y$ prácticamente contituyen una verdadera síntesis de su cristología?

Muchos comentaristas se han mostrado siempre intrigados en conjeturar si la razón por la que Mateo ha eliminado estas palabras se debe a la existencia y uso de una fuente o colección, oral o escrita, de (testimonia) veterotestamentarios, utilizados en las catequesis mesiánicas de las escuelas judaicas o de las primitivas comunidades cristianas, en las que habrían sido omitidas ". Otros permanecen desconcertados sin más ante tal omisión ". Sin embargo, tal supresión, probablemente voluntaria, favorece el sentido enfático del $\tau p \alpha \hat{\sigma} \varsigma$ (entendiendo el 'ânî del TM como 'ânaw, como hacen los LXX, Aquila, Peshitta V.T. y Targum) y manifiesta el interés de Mateo en alejar de Jesús todo rasgo o actuación que pudiera confundir su poder salvador y su justicia con la idea política que el judaísmo se había forjado sobre el Mesías: un guerrero y libertador político de Israel y vengador de sus enemigos. Es el ideal del Mesías que Satán y Pedro habian propuesto a Jesús y que éste había rechazado (Mt 4 , $5-7 ; 16,22-23)$. De este modo la figura del Rey mesiánico manso $y$

6. Cfr. P. Zarelia, "L'entrata di Gesù en Gerusalemme nella redazione di Matteo (21, 1-17)": La Scuola Cattolica 98 (1970) 96; W. RothfucHs, op, cit. 83.

7. Cfr. K. Stendahl, op. cit. 119; G. Bornkamm-G. Barth-HJ. Held, op. cit. 121, 32-35; W. TrILlING, Das Wahre Israel (Leipzig 1959) 143-153.

8. Cfr. P. BonnaRd, op. cit., 303; R. H. Gundry, op. cit., 151-185, donde ofrece una extensa crítica sobre las hipótesis en torno a las citas veterotestamentarias en Mateo y su origen.

9. Cfr. P. Zareila, loc. cit., 96 , nota 30 , quien lo recoge de G. BohinкAMM - G. BARTh - H. J. HELD, op 
humilde ocupa el centro del relato y centra la atención del lector en el significado del suceso ${ }^{10}$.

Las palabras finales de la cita profética en Mateo no coinciden exactamente ni con el TM ni con los LXX. Está de acuerdo con los

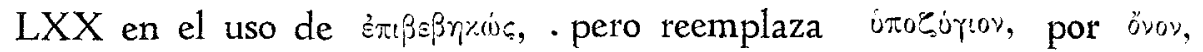
que corresponde más exactamente al vocablo hebreo hamôr (es un asno de trabajo o de montura: 'Gen 12,$16 ; 2 \overline{2}, 3 ; 23,35 \ldots$, traducido generalmente por owse en los LXX). Traduce el segundo 1 (= esti ), omitido por los LXX, pero concuerda con esta versión en aducir el término $\pi \tilde{\omega} \lambda$ ov $=$ asno joven o pollino), que en los LXX es la traducción ordinaria y correcta de 'ayir ". Por otra parte, mientras los LXX traducen por vénv la expresión semítica ben 'athonôth, Mateo transmite la frase hebrea completa, aunque en singular (= viós inogujiou), conforme al singular 'athôn del Targum y de la Peshitta V.T. ${ }^{12}$.

Aspectos teológicos-apologéticos de la cita de Zac 9,9 en Mateo.

Esta reelaboración mateana del texto profético del Zac 9,9 y la importancia que éste asume en el conjunto del relato dejan entrever los siguientes aspectos o caminos teológico-apologéticos del evangelista:

a) Las añadiduras y omisiones aportadas por Mateo en el relato de la entrada triunfal de Jesús en Jerusalén, tanto con relación a los elementos de la tradición evangélica, (=sinóptica y joannea) como al oráculo de Zac 9,9, para conformar el texto a la profecía, tienden a concentrar la atención del lector en el significado del suceso más que en el acontecimiento mismo ${ }^{13}$.

10. Cfr. G. Bornkamm - G. Barth - H. J. Held, op. cit, 121-122; O. DA Spinetoli, Matteo (Perugia 1971) 474; J. Dupont,' 'L'entrée messianique de Jésus à Jerusalem": Assamblées du Seigneur, n. 37 (Bruges 1965) 49.

11. H. W. KuHN, "Das Reitter Jesu in der Einzugsgeschichte der Markusevangelium": Zeitschrift fïr die Neutestamentliche Wissenschaft. 50 (1959) 82-91 y O. MICHEL, "Fine philologische Frage zur Einzugsgeschichte": New Testament Studies 6 (1959/60) 81-82) han refutado decisivamente la tesis de W. Bauer "The 'Coult' of Palm Sunday: Der Palmesel": Journal of Biblical Literature, 72 (1953) 220-229, según el cual, fuera de un contexto zoológico, como en Mc 11,2 y par., $\pi \tilde{\omega} \lambda_{0} \varsigma$ equivale a "caballo".

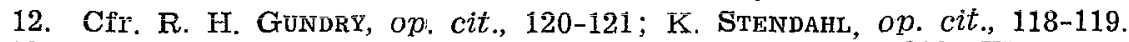

13. Cfr. P. Zarella, loc cit., 97-98; P. Bonnard, op. cit., 302; W. GruN- 
b) La entrada de Jesús en Jerusalén constituye el cumplimiento exacto, en toda su plenitud, del oráculo profético mesiánico de Zac 9,9-10. Por tanto, Jesús es el Rey Mesías, anunciado por el profeta, que entra en su ciudad en calidad de rey davídico ${ }^{14}$; el modo y las condiciones en que Jesús ha querido hacer su entrada en Jerusalén caracterizan el suceso como un acto propiamente mesiánico. Al realizar este acto, Jesús se aplica voluntariamente esta profecía y su enseñanza; El mismo es quien toma la iniciativa de esta puesta en escena, sin serle impuesta por ningún apremio externo. Con ello el evangelista deja entender que, incluso los mínimos detalles, tales como el montar Jesús sobre los dos animales a la vez, estaban previstos en los planes de Dios y, por tanto, tenía que suceder realmente así ${ }^{15}$.

c) Aunque la idea “Jesús es el Rey Mesías, anunciado por el profeta", ocupa en parte el centro del relato, no parece que Mateo ponga el acento en el título de "Rey» en cuanto tal, sino en la idea de "Rey manso y humilde», oculto, pacífico. De hecho Mateo desarrolla este pensamiento paradójico, presente ya en el vaticinio de Zac 9,9-10, según el cual el equipaje irrisorio, que caracteriza su entrada o entronización, revela las disposiciones de ánimo del Mesías: es Rey lleno de mansedumbre. Las curaciones de enfermos en el templo y el canto laudatorio de los niños (Mt 21, 14.17) acentúan de nuevo la mansedumbre de Jesús (cfr Mt I I,25-30). Es el Mesías-Rey que viene a su ciudad — personificación de Israel - no como dominador o conquistador glorioso y potente, sino como un rey bondadoso y portador de la paz, eliminando los caballos, los carros y los armamentos

DMANN, op. cit., 449: "el exacto cumplimiento de la profecía es para Mateo más importante que la posibilidad y claridad gráfica del suceso".

14. La denominación "Hijo de David", aplicada a Jesús, es otro de los temas predilectos de Mateo (cfr. $1,1.6 .17 ; 9,27 ; 12,23 ; 15.27 ; 21,9.15 \ldots$ ). Suele estar asociada al tema de la dignidad regia de Jesús o a las curaciones - misericordia. Cfr. A. G. Hebert, The Throne of David (London 1956); E. LOHSE, "Der König aus David Geschlecht": Abraham unser Vater (Festschrift für O. Michel) (Leiden-Köln 1963) 337-345; A. Deschamps, "Le Messianisme Royale dans le Nouveau Testament": L'attente du Messie (Bruges 1954) 57-84; Sh. E. Johnson, " De Davidic-Royal Motiv in the Gospels": Journal of Biblical Literature 87 (1968) 136-150, etc. 15. Cfr. E. HaENCHEN, Der Weg Jesu. Eine Erklärung des MarkusEvangelium und der kanonischen Parallelen (Berlin 1960) 377; D. M. Stanley, loc. cit., 103-106; W. Trilling, "Der Einzug Jesu in Jerusalen (Mt 21, 1-17)": Neutestamentiliche Aufsätze (Festschrift J. Schmid) (Regensburg 1963) 304 ; W. GRUNDMANN, op. cit.; 148-149; F. F. BRUCE loc. cit., 339 ; R. S. McConNelL, op. cit, 128-129. 
(cfr Mt 26, 52-54). Su dulzura y mansedumbre es la que evoca el oráculo de Isaías $(42, I-4)$, citado por el mismo evangelista $(\mathbf{I} 2,18-2 \bar{I})$. La mansedumbre de Jesús (Mt i I,29), Rey Mesías (Mt 2,2), que en el camino hacia la cruz (Mt 27, I r.22.29.37) renuncia al poder y majestad que le corresponde como juez escatológico del mundo (Mt 25,34. 40, donde ("el Juez) es caracterizado como "Rey»), juega un papel importantísimo en la pintura mateana de Jesús ${ }^{16}$.

d) El hecho de que Jesús; como Mesías-Rey, entre en Jerusalén no sobre caballo y con carros de combate, montura y compañía de los reyes impíos y de los conquistadores (cfr Jer 17,$25 ; 22,4$; I Mac I, I 7 ...), sino sobre un asno, característica de la montura del rey humilde y pacífico, no es solamente irrisorio. Contiene otro aspecto paradójico positivo, que evoca la montura tradicional de los patriarcas, héroes y reyes de Israel (cfr. Gén 22,3: Abraham; Ex 4,20: Moisés; Juec 5,10; ro,4; I 2, I4; 2 Sam I8,9: Absalón; I Rey I,33+38.45: Salomón) y dice relación no sólo con el vaticinio de Zac 9,9-10, sino también con la bendición de Jacob a Judá (Gén 49,I I), elementos ya interpretados mesiánicamente con relación a Zac 9,9-1o en el tardío judaísmo ${ }^{17}$.

Por eso no es inverosímil ${ }^{18}$ suponer que Mateo, recogiendo el pensamiento judaico contemporáneo ${ }^{19}$, haya querido relacionar y pre-

16. Cfr. G. BornKamm - G. Barth - H. J. Held, op. cit., 122; P. Zarella, loc. cit., 97; W. Trilling, loc cit., 304-305; W. Grundmann, op. cit., 449 ; R. S. Mcconnell, op. cit., 128; O. DA SPINEToli, op. cit., 474; W. RoTHFUCHs, op. cit., 82-83, 125, 133, quien insiste en que el vocablo $\pi$ pubs insinúa la idea de "ocultamiento" (Verhüllung).

17. Cfr. p. 13 .

18. Cfr. W. Trilling, loc. cit., 304-305; P. Bonnard, op. cit., 303; sin embargo, J. Dupont, loc. cit., 49, nota 1, sostiene que en Mateo tal reinterpretación no se da al nivel redaccional, ya que el evangelista omite el "salvador y justo".

19. Es notorio - contra la afirmación de G. Barth, en G. Bornkamm G. BARTh - H.J. Held, op. cit., 122-, que las tradiciones rabínicas son ordinariamente mucho más antiguas de lo que aparecen. Si por otra parte interpretaban mesiánicamente algún texto veterotestamentario, considerado también mesiánico por los cristianos, esto suele ser índice de que tal tradición es antigua, ya que la tendencia judaica fue ir relegando al olvido aquellos textos que los cristianos concebían como mesiánicos.

20. Los comentarios de Mateo suelen aceptar, en general, esta reflexión midráshica en algunos relatos de la Infancia, tentaciones de Jesús en el desierto, sermón de la Montaña, etc. Sín embargo, G. STrecker, op. cit., 76, niega toda tipología Moisés Cristo en el primer evangelio. 
sentar también aquí a Jesús como nuevo Moisés que viene a salvar a su pueblo ${ }^{20}$ y aludir incluso al cumplimiento de las antiguas promesas referidas a Judá-David ${ }^{21}$. Tal reinterpretación de Gén 49, I I, de ser cierta, podría explicar la inclusión de los dos animales de montura, el asna y su pollino, en el relato mateano $(2 \mathrm{I}, 2.7)$, sin necesidad de recurrir a un ignorado paralelismo de los miembros en Zac 9.9, difícil de concebir en un escritor semita y en un evangelio dirigido principalmente a lectores de formación judaica. Sin embargo, la tradición judaico-rabínica en conexión con el sentido mesiánico de Gén 49, I I sólo conoce una bestia ${ }^{22}$.

e) No es ajeno a la pluma de Mateo -en relación con la tradición rabínica ${ }^{23}$ - el motivo polémico apologético de la ingratitud e indignidad del pueblo judío, que rehusa aceptar a su Mesías- Rey en su venida. Jesús, en cuanto realizador de las promesas divinas, viene a Jerusalén, la personificación de Israel. Pero la ciudad responde fríamente, limitándose a preguntar quién es $(2 \mathrm{I}, \mathrm{IO})$. A pesar de que sus habitantes son informados por la multitud sobre la personalidad del que entra en ella (2 I, I I), apenas se asocian a las aclamaciones de los que le acompañan. Al contrario, en las personas de sus representantes, los sumos sacerdotes y los escribas, murmuran y se oponen al coro de (pobres» y niños, que reconocen en Jesús al Mesías (2 I, I 4-I 7). La Jerusalén oficial desconoce a Jesús, rehúsa aceptar al enviado de Dios, que le anuncia la salvación escatológica. Como en el relato de la venida de los Magos $(2, \mathrm{I}-4)$ con el que guarda muchas semejanzas ${ }^{24}$, la que debería ser "ciudad del gran Rey» se convierte en enemiga y culpable en extremo. La escena ante el pretorio de Pilato $(27, \mathbf{1}$ I. I7$21.37 \cdot 42)$ no hará más que llevar hasta las últimas consecuencias la actitud adoptada al iniciarse el camino de Jesús hacia la cruz: oposicion tenaz y condenación de su Rey, cuya mansedumbre preanuncia ya su destino.

\section{(Continuará)}

P. C. Mateos

21. Afirma esta referencia, sin confirmarla razonablemente, J. BLENkINsopp, "The Oracle of Judah and the Messianic Entry"..., 55-64. Cfr. además, W. Trilling, loc. cit., P. Zarelda, loc. cit., 97.

22. Cfr. K. Stendaht, The School of St Matthew..., 119; O. Mrchel, övoc: Theologisches Wörterbuch zum Neuen Testameni, $\mathbf{v} .284$.

23. Cfr. p. 13.

24. Cfr. D. M. Stanley, loc. cit., 97; P. Zarella, loc. cit., 103;W. RotHFUCHS, op. cit., 125. 